\title{
Untreated Small Lymphocytic Lymphoma
}

National Cancer Institute

\section{Source}

National Cancer Institute. Untreated Small Lymphocytic Lymphoma. NCI Thesaurus.

Code C132016.

A finding of small lymphocytic lymphoma that has not been treated. 